\title{
Call Centre Job Differences
}

\author{
Althea Jansen \\ Chris William Callaghan \\ University of the Witwatersrand, School of Economic and Business Sciences \\ Email: chris.callaghan@wits.ac.za
}

\section{Doi:10.5901/mjss.2014.v5n20p466}

\begin{abstract}
This research tested theory that predicted differences in the relationships between perceptions of management, satisfaction and performance by call centre job type. A sample of a hundred and ninety respondents was drawn from South African call centres. Findings suggest that outbound call centre agents are significantly more job dissatisfied than inbound agents, along certain dimensions. Outbound agents, sales agents and after service agents were found to rate their performance quality significantly lower than the rest of the cohort; in contrast, inbound agents and customer queries agents were found to rate their performance more highly. On the basis of the findings it is argued that assumptions of homogeneity in call centre work is problematic. It is recommended that different management strategies be built around different types of call centre work, that are responsive to the needs of those engaged in each type of work. It is also recommended that job enrichment be applied to all types of call centre work to potentially increase variability in tasks, which might increase autonomy and job satisfaction in this type of work.
\end{abstract}

Keywords: learning style; field of study; length of tertiary study; gender; age; learning language experience

\section{Introduction}

The dominant tension between the opposing goals of efficiency and service of call centres has a long history (Robinson \& Morley, 2006). The implications of this tension are multiple. Based in the Taylorist scientific management methodology, call centres typically manage using information about 'hard' measures, such as call volumes, as well as 'soft' measures such as the rapport between agents and customers, reflecting 'emotional labour' (Robinson \& Morley, 2006). However, for Wallace, Eagleson \& Waldersee (2000:174):

Balancing the competing objectives of efficiency and service typically requires management compromises to be made. However, some call centres have found that a compromise is not necessary. By using a "sacrificial HR strategy", they achieve both efficiency and high levels of service at the same time. This is possible because part of the sacrificial HR strategy is the deliberate, frequent replacement of employees in order to provide enthusiastic, motivated customer service at a low cost to the organization.

It is possible that if this phenomenon is characteristic of call centre work, then there is a human cost involved. Call centre work typically entails emotional labour (Wallace et al., 2000; Robinson \& Morley, 2006), which "requires one to induce or suppress feeling in order to sustain the outward countenance that produces the proper state of mind in others" (Hochschild, 2003:7). Call centre work is, however, also not homogenous (Taylor, Hyman, Mulvey \& Bain, 2002).

There are primarily three core types of call centre agent work: (i) completing transactions, (ii) generating sales, (iii) and providing solutions to and advice on relatively complex or technical issues (Wallace et al., 2000). For Wallace et al. (2000:180) "different categories of tasks generate different management challenges" as the "optimal trade-off between service and efficiency will be different for each category of call centre task". Similarly, there are differences in the work tasks performed by inbound versus outbound call centre agents.

Inbound agents typically perform tasks related to customer service, where customers call to enquire about accounts and sales or where clients call in response to marketing efforts, technical support and where agents field calls relating to the use of products and services (Rod \& Ashill, 2013). Inbound call centre tasks can be more complex than outbound tasks such as telemarketing, which usually uses standardised scripts and content (Rod \& Ashill, 2013). Inbound calls are therefore typically more varied in nature (Rod \& Ashill, 2013).

Despite much literature that relates to different aspects of call centre work, limited work exists on the differences in the structure of call centre agent perceptions of management, satisfaction and performance according to different types of 
call centre agent work in the South African context. This study therefore investigated these differences for call centre agents that worked in (i) sales, (ii) after sales service, (iii) customer queries and (iv) call routing work. Differences in sales call centre work by inbound versus outbound were also investigated.

The objective of this work was therefore to test theory that predicts differences between these different types of call centre work and the perceptions of management, satisfaction and performance of call centre agents. The research problem addressed in this research is therefore the lack of knowledge about differences in call centre management effects between different types of call centre work in the South African context. This knowledge is considered important for the following reasons.

Firstly, differences between tasks associated with different types of call centre work might be reflected in different potentialities for empowerment and satisfaction, which may require different management styles and systems. Call centre agents may react differently to more or less appropriate management styles and systems.

Agents tasked with completing transactions deal with well-defined tasks, which might appropriately allow for a focus on efficiency rather than service; sales centres, however, may require agents to be given more latitude in deciding how to achieve outcomes and may require more of a balance between service and efficiency; and a solutions centre may need to provide a more personalised experience to customers that is focused on quality of service and effectiveness rather than efficiency (Wallace et al., 2000).

The potential for conflict between task and management processes may be "highest in a transactions centre that also relies on a high level of emotional labour by staff", "emotional labour comes about as staff deal with complaining and irate customers" (Wallace et al., 2000:180).

An additional challenge found to be associated with complaint resolution is that it approximates problem solving and is not straightforward, yet performance measurement systems in call centres tend to measure agents doing this "as if they performed only routine transactions" (Wallace et al., 2000:181).

A sub-optimal alignment between management style and systems and the nature of the tasks associated with different types of call centre work might have consequences in terms of job satisfaction and performance (Wallace et al., 2001). It is argued that management research has a societal obligation to reduce the human costs of work while developing knowledge and theory that can increase productivity across contexts.

Secondly, call centre research has investigated the experience of call centre work in different contexts, such as in India (Taylor, D'Cruz, Noronha, \& Scholarios, 2013), and has shown working conditions typically differ between call centres with domestic versus international clients (Taylor et al., 2013). These differences reflect differences along an international dimension. The investigation of these relationships in the South African context offers a test of theory that has been derived from different international contexts. The extent to which theory generalises into the South African context of call centre work with regard to the relationships under study at this time is unclear. This research therefore seeks to reduce the problem space around this lack of knowledge in this context at this time.

Thirdly, the integration of the South African economy with the global economy since the advent of democracy in 1994 has made it imperative for South African businesses to become more competitive, and responsive to the need for higher standards in the call centre industry, while at the same time reducing the potential human costs associated with certain types of call centre work.

Having provided an introduction to the research, the structure of the paper is now outlined. First, literature is reviewed that relates to the context of the research and provides a background to the theoretical framework utilised. Next, hypotheses are derived from the literature, based on theoretical relationships. After this, the methodology applied in the study is introduced and discussed. The results of the study are then reported and discussed. The paper then concludes with the provision of recommendations for theory and practice that are derived from the findings. The literature and theory that relates the relationships under study is now considered.

\section{Literature and Theory}

Inbound call centres have the potential to generate at least 10\% of total firm revenue from new product or service sales (Jasmand, Blazevic \& de Ruyter, 2012). However, firms typically fail to successfully align customer service and sales in their call centre operations (Jasmand et al., 2012).

Research suggests that sales agents typically believe that "additional selling is incommensurate with service, which creates a high mental barrier to blending the two tasks" (Jasmand et al., 2012:20). Although this differentiation considered by Jasmand et al. (2012) in their work relates to sales agents, it is argued that this tension between customer service and call volumes reflected in sales and other output measures is at the heart of the differences in how different call centre work types are managed; and that differences in management processes that are less suited to the different 
types of tasks associated with different types of work will be reflected in employee perceptions of management, satisfaction and performance.

Differences exist between call centre job types, yet within these job types, differences also exist between individuals. For instance, differences in individual personality have been found to be associated with differences in performance related to the use of sales forces automation systems (Cheng-Wu, Yang, Chen, Tseng \& Lee, 2013). Nevertheless, this research focuses on differences between call centre work types. The level of analysis in this work is therefore focused on differences in the type of call centre work that individuals perform. In order to understand these relationships, it is now necessary to define the terms used in this study.

A call centre is "a dedicated operation in which computer-utilising employees receive inbound, or make outbound, telephone calls, with those calls processed and controlled, either by an automatic call distribution (ACD) or predictive dialling system" (Taylor and Bain, 1999:102). This definition is characterised by the integration of telephone and other technologies which has facilitated their rapid growth over time through the enablement of "vigorous, direct selling techniques and by perceived dramatic savings in costs and overheads emanating from the centralisation of 'back office' customer servicing functions" (Taylor \& Bain, 1999:102). The dictates of competitive advantage have made it imperative for organisations to develop these centres in response to their large scale use by competitors (Taylor \& Bain, 1999).

Call centres have oftentimes been found to focus on cost reduction, with customer service delivery not given sufficient attention, despite managers' insistence that customer service delivery is their primary responsibility (Robinson \& Morley, 2006).

According to research findings, call centres have seemingly developed an "insatiable appetite for quantitative performance measures, despite their limitations, almost to the exclusion of all other performance measures" (Robinson \& Morley, 2006:284). According to Robinson and Morley (2006:285), call centres are able to:

[T]rack the number of calls per agent, the number of abandoned calls, the time taken to abandon, the average speed to answer calls, the occupancy rate of agents (the percentage of time agents handle calls versus waiting for calls to arrive), the service level (percentage of calls answered within a prescribed time frame), the identification of call waiting longest in a queue, the identification of the agent who has been sitting idle the longest, which agents are on calls, on breaks or completing post call wrap up work and how long the wrap up work is taking per call on average. All of this information is available on a real time basis as well as in cumulative report form.

This study focuses on call centre satisfaction data in order to offer a perspective of staff satisfaction. Insight into call centre work from the vantage point of the call centre agent differs substantially from Taylorist perspectives of call centre work (Taylor \& Bain, 1999).

The call centre literature, therefore, is not without its critical voice. The surveillance and monitoring of call centre work has been likened by some to 'prisoner surveillance'; to the re-emergence of 'dark satanic mills'; to Orwell's 'Big Brother surveillance' and to a range of dystopian and panopticon perspectives (Taylor \& Bain, 1999).

For Wallace et al. (2000:175), the "sacrificial HR strategy" is termed thus because "the enthusiasm and motivation of the front-line are sacrificed by management", and it is a strategy "because it involves a coherent set of management activities and attitudes, which together solve the efficiency/service conflict", where "emotional burnout and high turnover are tolerated, if not encouraged".

On the basis of these perspectives across time in the sector, the satisfaction perceptions of call centre staff is considered to be particularly important. The approach of leadership, or management, to staff is also considered to be especially important. Wallace et al. (2000) found that although most call centre team leaders and centre managers in their study identified themselves as being relations or task focused, the majority of both agents and team leaders regarded their direct supervisor to be task-focused and not relational.

The implications of this are important. Relational supervision may be important in a context where emotional burnout and exit is more likely to occur (Wallace et al., 2000). Nevertheless, the role of management, or supervision might, however, shape an individual's management style toward task-focus (Wallace et al., 2000). The majority of agents have been found to be primarily motivated by a desire to serve the customer, and derive satisfaction from interactions with peers and customers (Wallace et al., 2000).

However, agents reported high levels of stress, complaining also about the monotony of the work, yet were most dissatisfied with customer complaints, the latter contributing in many cases to emotional burnout, especially when supportive elements were absent from the work design and where interaction between staff is limited (Wallace et al., 2000).

Relations-oriented managers can prevent burnout by reducing role ambiguity, providing feedback, and can be sensitive to staff with problems and rotate staff to reduce stress, all in addition to providing training to lessen the stress associated with the job and with dealing with difficult customers (Wallace et al., 2000). The degree to which a manager is 
relational might be reflected in staff perceptions of their managers. The characteristics of a manager that are best suited to a specific type of call centre job are expected to be known to agents. Hypothesis 1 is therefore offered: that there is a significant difference in the characteristics of an ideal leader by call centre job type. Similarly, Hypothesis 2 is also proposed: that there is a significant difference in characteristics of a leader/supervisor by call centre job type.

However, the extent to which relations-oriented management is incentivised for call centre operations is not clear. The call centre research of Wallace et al. (2000:179) suggests that there is "a clear understanding [by call centre operators] of the savings that could be gained by turning over burnt-out staff rather than investing in programs targeting morale, commitment and enthusiasm"; by "deliberately selecting individuals whose intrinsic motivation was service, high service levels were assured and the need for the organisation to provide this motivation external to the employee was removed".

A quote from a manager in Wallace et al.s' (2000:178) study is illustrative of this approach: "We don't want people to stay past 18 months. By that stage they are burnt out and are no good". However, for a 'sacrificial HR strategy' to be implemented, according to Wallace et al. (2000), a call centre needs to:

[B]e skilled at selecting intrinsically motivated staff. They need to be able to design the tasks so that the agents have minimal need for organizational knowledge. Finally, they must excel at monitoring staff performance, including call monitoring and customer satisfaction measurement. Given these capabilities, a large labour pool and a strong external labour market, the sacrificial HR strategy will be sustainable and result in high levels of service and efficiency.

The implication of this is that the variability of work tasks is reduced.

However, Wallace et al. (2000) question the social impact of such a policy; social costs reflected in emotional dissonance and burnout might be unavoidable by-products of such a policy. Call centre work is inherently associated with emotional dissonance (the difference between expressed and felt emotions), which in turn contributes to burnout (Wegge, Van Dick \& von Bernstorff, 2010).

Other literature also illustrates the management of call centres using 'hard' or statistical processes. 'Lean six sigma,' a form of statistical quality control, is an example of this form of call centre management (Laureani, Anthony \& Douglas, 2010). Foci of dissatisfaction, however, might entail costs for call centre organisations. It is in this historical context of call centre work that knowledge of the satisfaction loci of different types of call centre workers could be considered particularly salient.

The types of work tasks typical of call centre work may be at the heart of the tensions reflected in scholarly work on call centres. In order to understand these tensions, it is perhaps important to understand more about the details and minutiae of call centre work.

Call centre management are responsible for relatively 'capital intensive' operations, with high numbers of call centre agents that typically work across different shifts (Robinson \& Morley, 2006). According to Wallace et al. (2000:182):

By replacing the traditional face-to-face contact by an electronic one, technology facilitates micro level management at no perceived extra cost. Continual control can be maintained over all call times, call volumes and virtually every activity the employee performs. Additionally, technology allows monitoring of the quality of the agents' interactions. Supervisors have the ability to assess agent performance by randomly 'dropping in' on their calls or computer screens. Thus agents can be monitored closely for performance and burnout and appropriate interventions made.

Technology has enabled radical changes which range from work processes to the way research and development is undertaken (Callaghan, 2014). Further, because technology now incorporates product and service knowledge, agents are less dependent on skills other than a strong service orientation; in contexts of relatively high unemployment, a relatively large pool of recruits is available to call centres (Wallace et al., 2000).

This reliance on the 'external labour market' rather than 'internal labour markets' is typically associated with a more transactional than relational psychological contract between call centres and agents (Wallace et al., 2000).

Certain types of call centre work may be more likely to be managed using a 'sacrificial HR strategy', following Wallace et al.s' (2000) logic. For instance, if there are two axes that dominate in performance (efficiency and service) for most work, then for sales agents there is a third: sales. The use of three axes of performance may therefore have implications for the management of these agents that may differ from other forms of call centre work. If work is more complex, it may offer more opportunities for motivation (Wallace et al., 2000).

Inbound call centre work also includes dealing with customers from the same company; agents may be allowed to be more authentic, with less rigid emotional display rules than outbound agents, where they are allowed to express negative emotions in certain situations (Bongard \& al'Absi, 2003). It is possible that the higher levels of autonomy associated with this type of inbound work may be associated with higher levels of job satisfaction. Individuals typically pick a career based on an assessment of both internal (intrinsic) and external (extrinsic) factors (Coldwell \& Callaghan, 
2013a); it is possible that individuals may choose to work either in inbound versus outbound work.

Differences in objective working conditions in call centres have been found to be significantly associated with differences in work motivation (Wegge, Van Dick, Fisher, Wecking \& Moltzen, 2006). To the extent that job satisfaction is expected to be associated with complex forms of work (Wallace et al,. 2000), Hypothesis 3 is proposed, that there is a significant difference in job satisfaction by call centre job type. Differences in satisfaction associated with differences in working conditions that differ by the type of call centre job are considered to be reflected in differences in work motivation.

Call centres "of the future could and should provide challenging work and constant opportunities for training, learning, and development" (Wegge et al., 2006:81). The "traditional focus on efficiency as the key performance parameter in inbound call centres is an antithesis to the goals firms try to achieve with service sales alignment" (Jasmand et al., 2012:20). Firms should, instead, "reconsider a strong focus on efficiency because increased customer satisfaction and successful cross-/up-selling may lead to long-term benefits, such as enhanced customer retention and loyalty...[when] assessing the profitability of a service-sales alignment, firms should consider long-term implications in addition to immediately visible efficiency losses" (Jasmand et al., 2012:20). Informal resistance to the imposition of formal goals can emerge, with productivity implications (Coldwell \& Callaghan, 2013b).

Wegge et al. (2006:80) argue that there are real advantages to call centres that increase the motivational potential of call centre work, in the form of (i) real benefits at the operational level to both organisational and agents which result from job designs that "facilitate greater involvement, participation, and autonomy; and more sophisticated call centre handling requirements in the form of low volume, long duration, high skill, phone-based customer interactions"; and (ii) increased work motivation and organisational identification "with regard to job satisfaction, OCB, health complaints, emotional exhaustion, and personal accomplishment".

Types of call centre work may therefore differ in the extent to which they provide 'efficiency' versus 'service' orientations. The chance to combine telephone work with other, and particularly more challenging work might reflect a more empowered working context (Zapf, Isic, Bechtoldt \& Blau, 2003). This might be the case when technical assistance is required from agents and they need to perform relatively complex tasks (Zapf et al., 2003). It is perhaps more likely that inbound agents experience a more empowering context than outbound agents or sales agents.

If inbound call centre agents are exposed to calls that are generally more varied (Rod \& Ashill, 2013) then it is expected that they will have more autonomy in the choices they make in their responses. Higher levels of autonomy might be associated with higher levels of satisfaction (Hackman \& Oldham, 1976), but differences in performance between different call centre job types might be more difficult to predict. It is possible that the performance of an individual can be better measured (and controlled) when the telephonic interaction is more scripted, or exposed to less variance. Typically, outbound calls are associated with less variance (Rod \& Ashill, 2013). It is possible that outbound calls might, in general, be subject to higher levels of surveillance, such as information tracking systems, than incoming calls. What is not clear, however, is whether this is reflected in the self-ratings of individual call centre agents of their own performance. Hypothesis 4 is therefore proposed, that there is a significant difference in job performance quality by call centre job type.

Having discussed the theoretical framework of the study and the hypotheses tested in this study, the methodology applied in this research is now considered.

\section{Research Methodology}

On the basis of the associative structure that emerged from the analysis, a perspective of the patterns of perceptions of each of the different types of call centre job types emerged, within the structure provided by the hypothesis testing process. Applying the principles of convergent and divergent validity (Campbell and Fiske, 1959), using many dimensions of input, a profile of the different types of perceptions of different types of agents was found to emerge.

The population for this study was defined as individuals working in a call centre in South Africa, Gauteng. Both inbound and outbound call centres were targeted. In total, nineteen call centres were approached and nine participated in the study; representing a $47 \%$ response rate of organisations sampled. The aim of the data collection process was to sample a mix of both inbound and outbound call centres in the Gauteng region. Organisations were selected on the basis of convenience. The sampling strategy employed was a non- probability volunteer sampling strategy which relied on employees willingness to participate in the study. This worked well within the limitations of both time and financial resources (Zikmund, 2003). However, the challenge with this was that the sample may not have been entirely representative of the population (Rosnow \& Rosenthal, 1991).

Previous research has found a high correlation between customers' and call centre employees' perceptions of service quality (Malhotra and Mukerjee, 2004). This suggests that it is possible for self- reports of employees to be a reliable method of assessing customer service orientation. 
Call centre agents who indicated that they dealt with outbound calls or mostly with outbound calls were classified as outbound agents for the purposes of the analysis. The same was done with the inbound agents.

Differences in a range of different scale items were tested against differences in call centre work type. The scales used in this study are discussed as follows.

Implicit Leadership Theory (ILT) scales were used to pick up differences in perceptions A revised version of the original 41- item scale developed by Offerman, Kennedy and Wirtz (1994) was used to measure ILT (Epitropaki \& Martin, 2004). According to Offermann et al. (1994), almost all subscales have good reliability estimates in previous research, with Cronbach alphas ranging from .75 to .93 , In part one, participants are asked to rate different traits based on their idea of how characteristic they are of a good leader and in part two, how characteristic it is of their leader. Each trait is rated on a 7- point scale ranging from not at all characteristic to extremely characteristic. Examples of this include traits such as intelligence or sincerity.

Leader Membership Exchange (LMX) scales using a revised version of the LMX-7 were used as recommended by Graen \& Uhl- Bien (1995).

Psychological empowerment was measured using competence items that were adapted by Spreitzer (1995).

Organizational commitment was tested using a revised version of Meyer and Allen's (1997) 18- item organizational commitment scale.

For the measurement of employee job satisfaction, a revised version of Warr, Cook \& Wall's (1979) 15- item overall job satisfaction scale was used in the form of a 7- point scale and participants are asked to rate each item. An example of this would be the physical work conditions.

Customer Orientation was measured by using the 12 positively worded items from the Sales Orientation/ Customer Orientation (SOCO) scale (Saxe and Weitz, 1982). The coefficient alpha estimate for this scale was .93, and the parameter estimates ranged from .50 to .81 .

Turnover intention was measured with a four-item measure of turnover intention derived from Mitchel's (1981) turnover study in a service industry. A Cronbach's alpha of .81 have previously been achieved for these scales utilizing the Mitchel (1981) turnover intention instrument, in other research involving retail managers.

Social desirability was measured using a revised, shorter version of Marlowe-Crowne's Social Desirability Scale offered by Ballard (1992); this measures the extent to which individuals present themselves in a favourable manner regardless of their true feelings. This scale consisted of 11 items. It was created from Ballard's (1992) short form of the Marlowe-Crowne Social Desirability Scale.

The statistics reported in Table 1 highlight certain characteristics of the sample. The gender mix was fairly even with only a $7 \%$ difference in representation. Females, however, are the majority. More than $35 \%$ of the sample had no more than school level educational outcomes. The average age was 28 years. The average tenure was 3 years but may have been around 2 years if a few outliers were excluded in the calculation. This suggests that many do not stay in their jobs for many years.

Table 1. Demographic Characteristics of the Sample

\begin{tabular}{clcc}
\hline Variable & & Number of Respondents & Percentage of Respondents \\
\hline Gender & Male & 89 & $46 \%$ \\
& Female & 101 & $53 \%$ \\
& No response & 1 & $1 \%$ \\
& Black & 110 & $57 \%$ \\
& Coloured & 37 & $19 \%$ \\
& Indian & 24 & $13 \%$ \\
& White & 20 & $10 \%$ \\
& Asian & 0 & $0 \%$ \\
& No response & 1 & $1 \%$ \\
& Grade 10 & 2 & $1 \%$ \\
& Grade 12 & 67 & $35 \%$ \\
& Diploma & 33 & $17 \%$ \\
& Some university time & 34 & $18 \%$ \\
& University degree & 21 & $11 \%$ \\
& Postgraduate diploma & 15 & $8 \%$ \\
& Some business school time & 11 & $6 \%$ \\
& Postgraduate degree & 1 & $1 \%$ \\
& Other & 5 & $3 \%$ \\
& No response & 3 & $2 \%$ \\
\hline
\end{tabular}




\begin{tabular}{clcc}
\hline Inbound vs Outbound & Outbound & 1 & $1 \%$ \\
& Inbound & 71 & $37 \%$ \\
& Mostly outbound & 29 & $15 \%$ \\
& Mostly inbound & 85 & $44 \%$ \\
& No response & 5 & $3 \%$ \\
Nature of Work & Sales-call potential customers & 19 & $10 \%$ \\
& Sales-potential customers call us & 3 & $2 \%$ \\
& Sales-we call \& they call & 4 & $2 \%$ \\
& After sales service & 9 & $5 \%$ \\
& Queries from customers & 146 & $76 \%$ \\
& Routing calls & 8 & $4 \%$ \\
& No response & 3 & $2 \%$ \\
& Less than 30sec & 4 & $2 \%$ \\
& 30sec-1min & 5 & $3 \%$ \\
& 1min-2min & 16 & $8 \%$ \\
& 2min-5min & 123 & $64 \%$ \\
& More than 5min & 40 & $21 \%$ \\
\hline Nene (in years) & No response & 4 & $2 \%$ \\
\hline Tenure (in years) & Mean= 28 & & \\
\hline
\end{tabular}

\section{Findings and Discussion}

Hypothesis 1. There is a significant difference in the characteristics of an ideal leader by call centre job type.

According to the point biserial results, individuals engaged in outbound sales calls were found to rate the importance of understanding in a good business leader significantly higher than inward bound sales agents $(.1866 ;$; <.01). This might reflect a need for understanding experienced by outbound agents, who may be required to display higher levels of emotional labour than inbound agents. It is possible that outbound agents in this context may require relatively more relational support in the form of understanding from managers.

On the criteria relating to the importance of knowing where one stands with their leader, or knowing how satisfied a leader is with what one does, inbound sales call centre agents were significantly more likely to rate this a characteristic of an ideal leader than outbound agents $(.163 ; p<.024)$. This might suggest that inbound sales agents may have a higher preference for feedback than outbound sales agents. Alternatively, this result might suggest that outbound agents already receive relatively high levels of feedback.

After service agents were found to rate the energetic characteristics of an ideal leader significantly lower than the rest of the cohort $(-.169 ; p<.019)$. After service agents differ from sales agents in that they might be less exposed to the emotional labour demands faced by sales agents. It is possible that a more passive leadership style might be more acceptable to after service agents than their counterparts.

Agents that primarily handle customer queries were found to rate the ability to know whether a leader is satisfied with performance significantly higher than the rest of the cohort $(.167 ; p<.021)$. These agents might also value feedback to a greater extent than their colleagues in other forms of call centre work.

Agents that primarily route calls were found to rate knowing job problems and needs higher as a characteristic of an ideal leader than the rest of the sample $(.166 ; p<.021)$. This might reflect this characteristic as a priority in the work that they do.

On the basis of these significant associations, the null hypothesis was rejected and the alternative hypothesis was accepted.

Hypothesis 2. There is a significant difference in the characteristics of a leader/supervisor by call centre job type.

Sales agents were found to be significantly more likely to rate their managers as less hard working $(-.189 ; p<.009)$. It is possible that the pressures associated with sales performance might make these agents more sensitive to the fact that their supervisors are not under the pressure they are.

After sales service call centre agents were found to be significantly more likely to report their current managers to be less knowledgeable $(-.222 ; p<.002)$, clever $(-.168 ; p<.02)$, dedicated $(-.292 ; p<.0001)$, and motivated $(-.164 ; p<.024)$. They were also more likely to rate their managers as significantly less dynamic $(-.162 ; p<.025)$ and more manipulative $(.160 ; p<.028)$, loud $(.186 ; p<.01)$, selfish $(.216 ; p<.003)$, conceited $(.167 ; p<.021)$, and masculine $(.146 ; p<.047)$. These agents were also significantly more likely to report having significantly lower levels of autonomy in how they did their jobs 
$(-.168 ; p<.022)$, as well as the opportunity for independence and freedom in how they do their jobs $(-.188 ; p<.009)$. After service agents were found to be significantly less likely to rate the item 'I have enough confidence in my leader that I would defend and justify his/her decision if he/she were not present to do so' as high as the rest of the cohort ($.158 ; p<.03)$.

Sales agents were found to be significantly more likely to report not feeling like 'part of the family' with their managers $(.164 ; p<.023)$. The pressures on sales agents to perform against measurable outcomes (sales) might make it more likely that a sacrificial strategy is used for sales agents. This might account for this result.

Customer queries agents were found to be significantly more likely to rate their managers significantly higher in terms of dedication $(.156 ; p<.032)$, motivation $(.145 ; p<.045)$ and hardworking nature $(.192 ; p<.008)$. It might be possible that the enhanced variability in this type of call centre work (Rod \& Ashill, 2013), which may be associated with more autonomy and more choice in how an agent responds to calls, may result in more empowered and satisfied workers (Hackman \& Oldham, 1976). It is possible that these 'positive' perceptions of management reflect a more positive intrinsic state than is found for other types of call centre jobs.

Outbound sales agents were found to be significantly less likely to report trying to achieve their goals by satisfying their customers than were inbound sales agents $(-.146 ; p<.043)$. This result might also reflect the more 'controlled' nature of outbound sales work, and the lower levels of variability allowed in this type of work as opposed to inbound work.

On the basis of these results, it is argued that differences between the types of work that call centre agents do are reflected in different intrinsic profiles, which are also reflected in the perceptions of agents of their ideal managers as well as their current managers. Also aspects of these intrinsic profiles are the levels of satisfaction experienced by agents. These are considered as follows.

Hypothesis 3. There is a significant difference in job satisfaction by call centre job type.

With regard to satisfaction, outbound sales agents were significantly more likely to indicate that they were happy to 'spend the rest of their life' with their call centre than inbound agents $(.179 ; p<.013)$. This was a surprising result, given that outbound sales work tasks were expected to be more target-driven and to be more likely to be vulnerable to sacrificial management practices. A key to this paradox is perhaps offered by a further analysis of age effects. Outbound agents were found to report being significantly older than inbound agents $(.208 ; p<.004)$. Individuals handling customer queries were found to be significantly more likely to report being younger than the rest of the sample $(-.183 ; p<.012)$.

Because outbound sales agents were older, further tests were conducted to check if the relatively higher levels of satisfaction of these agents relative to inbound agents might be an artefact of the influence of age. Age was therefore included as a covariate in a process of Pearson partial correlation testing. With age controlled, this association was no longer significant at the five percent level (.121; $p<.098$; bootstrapped confidence intervals -.029 lower; .280 upper; 1000 iterations).

Rod and Ashill (2013) found age to be associated with lower levels of emotional exhaustion, or the perception of lower levels of emotional fatigue, although the effect seemed to be stronger for those in inbound $(\beta=-.021)$ versus outbound $(\beta=-14)$ call centre agent jobs. Similarly, those with more experience were also found to have lower levels of emotional exhaustion ( $\beta=-.21$ for inbound agents versus $\beta=-.14$ for outbound agents). These differences were not found to be statistically significant, however.

On the item 'I do not feel any obligation to remain with my current employer', outbound agents were found to be significantly more likely to agree, relative to inbound agents $(.144 ; p<.047)$. This result supports the notion that outbound sales agents might be more vulnerable to having the sacrificial strategy applied because of the ease of measuring their work outputs.

Inbound agents were found to indicate that they were significantly more satisfied with their physical work conditions $(.156 ; p<.03)$ than outbound agents. This result supports the same notion.

Outbound agents, however, were found to be more satisfied with the opportunities they have to use their abilities $(.151 ; p<.036)$.

After sales service agents were found to be significantly less likely to indicate that staying 'is as much necessity as desire' $(-.233 ; p<.002)$. After sales service agents were also found to be significantly more likely to indicate that they had 'given up doing something because I thought too little of my ability' (.143;p<.047).

Sales agents were found to be significantly more likely to be satisfied with industrial relations and the management of workers $(.155 ; p<.031)$. Given the higher potential likelihood that sales agents are exposed to a more intense working context where their performance (in terms of sales) can be monitored, the implications of this result are not clear.

Call routing agents were found to be significantly more likely to report not feeling a sense of 'belonging' to their managers $(.157 ; p<.031)$. It is possible that call routing agents reflect the values and relationship characteristics that are shaped over time by this type of work. 
If inbound agents are typically allowed to be more authentic, with less rigid emotional display rules than outbound agents (Bongard \& al'Absi, 2003) then inbound agents might be expected to experience more autonomy, and therefore more job satisfaction (Hackman \& Oldham, 1976). However, if sales agents are more likely to be exposed to a sacrificial strategy, it is possible that the 'high volume' selection process coupled with high turnover might over time 'select' for individuals that are robust to dissatisfaction effects. A tension seems to be present with regard to these different notions.

Sales agents were also found to be significantly more likely to report being satisfied with their chances at promotion $(.145 ; p<.045)$. However, sales agents were significantly less likely to report planning to stay with the company for 'quite a while' $(-.236 ; p<.001)$. Sales agents were also significantly more likely to report sometimes getting 'so irritated' that they think about changing jobs $(-.187 ; p<.01)$. Nevertheless, sales agents were found to be significantly more likely to report being satisfied with the attention paid to suggestions $(.147 ; p<.043)$. Outbound sales agents were also significantly more likely to indicate that they would turn down an offer from another company if it 'came tomorrow' versus inbound sales agents $(.172 ; p<.018)$.

On balance, despite these contradictory responses, these results seem to support the notion that outbound agents are relatively less job satisfied than inbound agents.

Call centre agents involved with routing calls were the only category of agent to be significantly more likely to respond significantly to the item 'My job activities are personally meaningful to me', although their responses were negative $(-.183 ; p<.011)$. Further research might indicate which dimensions of call routing work contribute to feelings of meaninglessness. It is tentatively suggested that if call routing work could be enriched then the job satisfaction of these agents might be improved. On the basis of these significant associations, the null hypothesis is rejected and the alternative hypothesis is accepted. Tested relationships between different call centre job types and call centre agent job performance are now discussed in relation to Hypothesis 4.

Hypothesis 4 . There is a significant difference in job performance quality by call centre job type.

According to Spearman Rho point-biserial correlation tests of association, individuals working as outbound call centre agents $(-.217 ; p<.003)$, sales agents $(-.247 ; p<.001)$ and after sales service agents $(-.150 ; p<.042)$ were found to be significantly more likely to rate the quality of their job performance significantly lower than other agents, while inbound call centre agents $(.214 ; p<.003)$ and customer queries agents $(.307 ; p<.0001)$ were found to have relatively higher levels of self-reported quality of performance. It is unclear why these differences are present. Further research might offer more insight into these differences, and their implications for performance quality.

In terms of quantity of performance, individuals engaged in customer queries reported significantly higher levels of self-reported performance $(.175 ; p<.016)$ and after sales service consultants were significantly more likely to report lower levels of performance $(.175 ; p<.016)$. Given that these questions required individuals to place themselves in relation to others in the company, it is possible that these responses captured some dimension of the relative performance perceptions that different types of call centre agents have of themselves.

Dimensions of perceived performance are expected to differ across different types of call centre work. Sales agents were significantly less likely to report trying to achieve their goals by satisfying their customers $(-.178 ; p<.014)$. Sales agents were also found to be significantly less likely to report trying to 'figure out what kind of product would be most helpful to a customer' $(-.220 ; p<.002)$, and to have a 'great deal of control over what happens in their departments' ($.171 ; p<.018)$. Sales agents were also found to be significantly less likely to report answering a customer's questions about products or services as correctly as they could $(-.293 ; p<.0001)$. It is possible that these are not dimensions of performance that are prioritised by call centres in sales work. Call routing agents were also found to be significantly less likely to report trying to 'figure out what kind of product would be most helpful to a customer' $(-.154 ; p<.032)$. Further research might indicate to what extent these dimensions of performance are truly irrelevant to sales and call routing work. It is recommended that call centre managers take into consideration the patterns of associations tested here and seek to tailor the characteristics of management to the specific nature of different types of call centre work. On the basis of these results it is argued that call centre work is not homogenous, and that there are certain differences, the knowledge of which might offer the opportunity to better match managerial processes to call centre work.

Given these significant associations, the null hypothesis is rejected and the alternative hypothesis is accepted.

\section{Concluding Remarks}

The objective of this research was to investigate potential differences in the perceptions of call centres agents of their management, job satisfaction and performance by differences by call centre job type.

It is possible that the results broadly reflect the influence of two mechanisms at work here: (i) that individuals more robust to the negative influences of certain types of work are 'selected' over time, and that a greater number of a certain 
type of individual eventually dominate in different forms of call centre work, or (ii) that individuals are shaped by the type of work tasks they do over time. It is argued that the associative structure tested in this study might offer further researchers knowledge of associations that reflect these two different effects in the South African call centre context. On the basis of these findings, it is argued that a 'sacrificial' strategy has no place in working contexts, not least because of the heterogeneous nature of different types of call centre work, which may require different types of management. Further, dissatisfaction cannot be considered to produce optimal call centre outcomes, according to theory. Further research should also investigate the social costs associated with burnout and the high turnover of call centre agents associated with the use of a sacrificial strategy.

\section{References}

Ballard, R. (1992). Short forms of the Marlowe-Crowne social desirability scale. Psychological Reports, 71(3f), 1155-1160

Bongard, S., \& al'Absi, M. (2003). Domain-specific anger expression assessment and blood pressure during rest and acute stress. Personality and Individual Differences, 34, 1383-1402.

Callaghan, C.W. (2014). R\&D Failure and Second Generation R\&D: New Potentialities. Mediterranean Journal of Social Sciences, 5(3), 11-24.

Cheng-Wu, C., Yang, H., Chen, C., Tseng, C., \& Lee, K. (2013). The Relationship between Personality Traits and Sales Force Automation Usage: A Review of Methodology. Human Factors and Ergonomics in Manufacturing and Service Industries, 23(4), 294-305.

Coldwell, D.A.L., \& Callaghan, C.W. (2013a). The Role of Internal and External Factors on Management Students' Subject Choices. South African Journal of Economic and Management Sciences, 16(3), 244-257.

Coldwell, D.A.L., \& Callaghan, C.W. (2013b). Formal and Informal Organizational Networks: Conflicts and Trade-Offs in Goal Attainment Propensities. Journal of Social Sciences, 35(3), 273-283.

Epitropaki, O., \& Martin, R. (2004). Implicit leadership theories in applied settings: factor structure, generalizability and stability over time. Journal of Applied Psychology, 89, 293- 310.

Graen G. B., \& Uhl-Bien, M. (1995). Relationship-based approach to leadership: Development of leader-member exchange (LMX) theory of leadership over 25 years: Applying a multi-domain perspective. Leadership Quarterly, 6(2), 219-247.

Hackman, J. R., \& Oldham, G. R. (1976). Motivation through the Design of Work: Test of a Theory. Organizational Behaviour and Human Performance, 16, 250-279.

Hochschild, A.R. (2003). The Managed Heart. London: University of California Press.

Jasmand, C., Blazevic, V., \& de Ruyter, K. (2012). Generating Sales While Providing Service: A Study of Customer Service Representatives' Ambidextrous Behavior. Journal of Marketing, 76, 20-37.

Laureani, A., Antony, J., \& Douglas, A. (2010). Lean six sigma in a call centre: a case study. International Journal of Productivity and Performance Management, 59(8), 757-768.

Malhotra, N., \& Mukherjee, A. (2004). The relative influence of organisational commitment and job-satisfaction on service quality of customer-contact employees in banking call centres. The Journal of Services Marketing, 18(2/3), 162-174.

Meyer, J. P., \& Allen, N. J. (1997). Commitment in the Workplace. Thousand Oaks, CA: Sage.

Mitchel, J.O. (1981). The effect of intentions, tenure, personal, and organizational variables on managerial turnover. Academy of Management Journal, 24(4), $742-751$.

Offermann, L.R., Kennedy, J.K., \& Wirtz, P.W. (1994). Implicit leadership theories: Content, structure and generalizability. Leadership Quarterly, S(l), 43-58.

Robinson, G., and Morley, C. (2006). Call centre management: responsibilities and performance. International Journal of Service Industry Management, 17(3), 284-300.

Rod, M., and Ashill, N.J. (2013). The impact of call centre stressors on inbound and outbound call-centre agent burnout. Managing Service Quality, 23(3), 245-264.

Rosnow, R.L., \& Rosenthal, R. (1991). If you're looking at the cell means, you're not looking at the interaction (unless the main effects are zero). Psychological Bulletin, 110, 574-576.

Saxe, R., \& Weitz, B. A. (1982). The SOCO scale: a measure of the customer orientation of salespeople. Journal of marketing research, 343-351.

Spreitzer, G. (1995). Psychological empowerment in the workplace: Dimensions, measurement and validation. Academy of Management Journal, 38(5), 42-1465.

Taylor, P., \& Bain, P. (1999). 'An assembly line in the head': work and employee relations in the call centre. Industrial Relations Journal, 30(2), 101-117.

Taylor, P., Mulvey, G., Hyman, J., and Bain, P. (2002). Work Organization, Control and the Experience of Work in Call Centres. Work, Employment \& Society, 16(1), 133-150.

Taylor, P., D'Cruz, P., Noronha, E., \& Scholarios, D. (2013). The experience of work in India's domestic call centre industry. The International Journal of Human Resources Management, 24(2), 436-452.

Wallace, C.M., Eagleson, G., \& Waldersee, R. (2000). The sacrificial HR strategy in call centres. International Journal of Service Industry Management, 11(2), 174-184. 
Warr, P. D., Cook, J. D. \& Wall, T. D. (1979). Scales for the measurement of work attitudes and aspects of psychological well- being. Journal of Occupational Psychology, 52, 129- 148.

Wegge, J., Van Dick, R., Fisher, G.K., Wecking, C., \& Moltzen, K. (2006). Work motivation, organizational identification, and well-being in call centre work. Work \& Stress, 20(1), 60-83.

Wegge, J., Van Dick, R., \& von Bernstorff, C. (2009). Emotional dissonance in call centre work. Journal of Managerial Psychology, 25(6), 596-619.

Zapf, D., Amela, I., Bachtolt, M., \& Blau, P. (2003). What is typical for call centre jobs? Job characteristics, and service interactions in different call centres. European Journal of Work and Organizational Psychology, 12(4), 311-340.

Zikmund, W. G. (2003). Business Research Methods (7th Ed.). United States of America: Thomson South- Western. 